\title{
Utilization of Solar Energy for Electricity Generation in Kurdistan - Koya City
}

\author{
Hawbash Hamadamin Karim*, Jahfer M. Smail, Hemn M. Salh \\ Department of Physics, School of Science, Faculty of Science and Health, Koya University, Iraq
}

Copyright $(2015$ Horizon Research Publishing All rights reserved.

\begin{abstract}
This paper studies a number of reasons that effect on the overall output electrical energy of a solar cell, to find the best angle at morning, noon and afternoon times in installing a solar cell system in Koya.. The study was conducted for three (3) months in Koya City- Kurdistan region of Iraq in 2014. It was found that the best Azimuth angle is between $\left(330^{\circ}-340^{\circ}\right)$ whereas the best incident angles are $27^{\circ}$ at the mornings, $60^{\circ}$ at the noon and $25^{\circ}$ at the afternoons in the Koya City. Moreover, the output electrical power that were produced from the solar cell was affected by weather, temperature, and raining as well.
\end{abstract}

Keywords Solar Cell, Digital Voltmeter, Ammeter and Computer

\section{Introduction}

Photovoltaic cell is a device that generates direct current (DC) electrical power measured in watts (W) or kilowatts (kW) from semiconductors when they are illuminates by photons. One important way to convert solar radiation into electricity occurs by the photovoltaic (PV) effect which was first observed by Becquerel [1]. The modern form of the solar cell was invented in 1954 at Bell Telephone Laboratories. Today, PV is one of the fastest growing renewable energy technologies and it is expected that it will play a major role in the future global electricity generation mix [2]. The theoretical studies have investigated several limitations that reduce the solar cell output efficiencies, and they give guidance to overcome these drawbacks and improve their efficiencies [3]. This paper examines some parameters which have noticeable impact on the output of solar cells.

\section{Methodology}

As mentioned in introduction this study works on some features in order to improve and find the best values of them to obtain a desirable output from solar cells. This paper particularly investigates the azimuth and incident angles as they are introduced below:

\subsection{Azimuth (AZI) Angle}

It is defined as the direction of the sun measured in the horizontal plane from north in a clockwise direction, as shown in figure (1) (thus east $=90^{\circ}$, south $=180^{\circ}$ and west $=$ $270^{\circ}$, whilst north can be 0 or $360^{\circ}$ ) [4]. In this work various azimuth angles were measured then the electrical output of the cell for each angles was recorded. In order to find the best azimuth angles for solar cells in Koya City. Results are shown in the next parts of this paper.

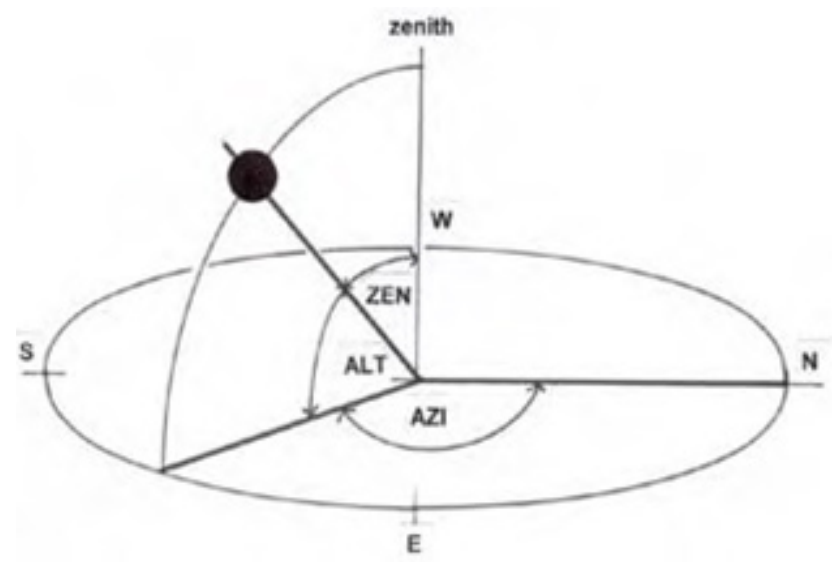

Figure 1. Definition of azimuth angles [4].

\subsection{The Incident Angle:}

The angle of incident is not a measured of the sun's position, but it measures the amount of radiation incident on a vertical surface. The angle of incidence is related to the solar altitude as follows:

$$
\boldsymbol{\theta}=90^{0}-\varphi
$$

Where $\boldsymbol{\theta}$ :-incident angle and $\boldsymbol{\varphi}$ :-Solar altitude. Together, the two angles provide useful information about the orientation of incoming sunlight on an object or structure, as shown in figure (2) [5]. In this work besides that the azimuth angles was worked on, the incident angles were changed for 
different values and at different times then measurements were recorded between the incident angle with output electrical power of the solar cell in Koya City. Measurements are shown in the next portions of this paper.

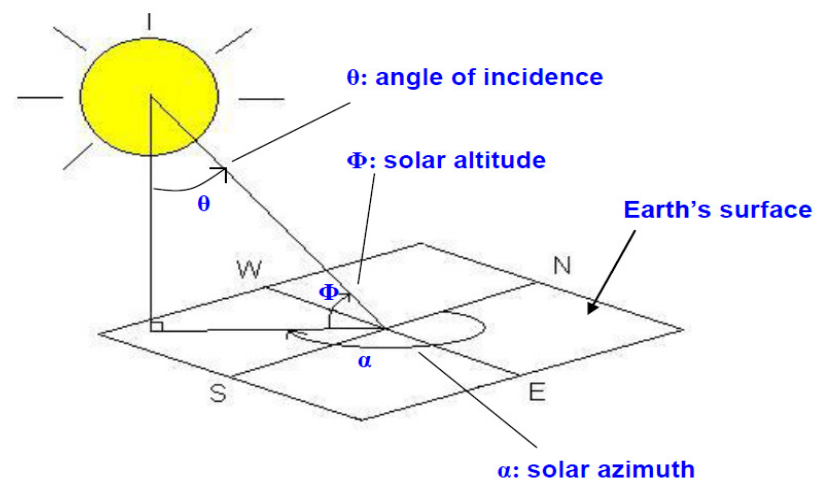

Figure 2. Solar geometry diagram [5].

\subsection{Location:}

In most practical work it must be considered the point location on the earth's surface as the center of the world: the horizon circle is assumed to be flat and the sky is a hemispherical vault. The sun's apparent position on this 'sky vault' can be defined in terms of two angles [4]. But this parameter does not have effects on this work because the work was conducted on one location

\subsection{Structural Loads:}

A structure that converts solar energy directly to DC is a solar panel. It supplies a voltage and a current to a resistive load (light, battery, motor) [4]. The power output of a solar panel depends on the resistance of the electrical load to which it is connected. In an open circuit situation (infinite resistance) the voltage of the solar panel will be high, but no current will flow and therefore no power is generated. In short circuit situation (zero resistance) current flows, but with zero voltage and so again no power is generated. These results all follow from Ohm's Law which gives the relationships between voltages, current, resistance, and power [6].

Power $=$ Current $\mathbf{x}$ Voltage $=(\text { Current })^{2} \times$ Resistance

\section{Results and Discussion}

\section{1- Solar cell depends on Angles}

A cell's exposure to the sun is one of the most fundamental factors affecting how much electricity can produce. In general, the amount of light strikes a solar cell will vary during the day, even if there is no shadow, simply because the angle of the sun relative to the cells is changing throughout the day.

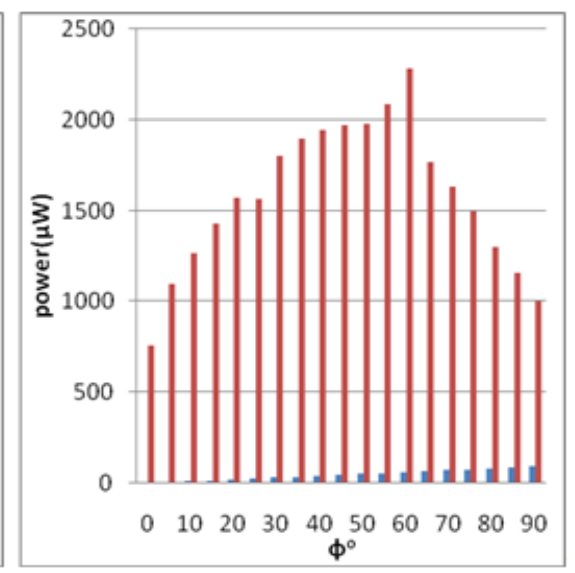

(b)

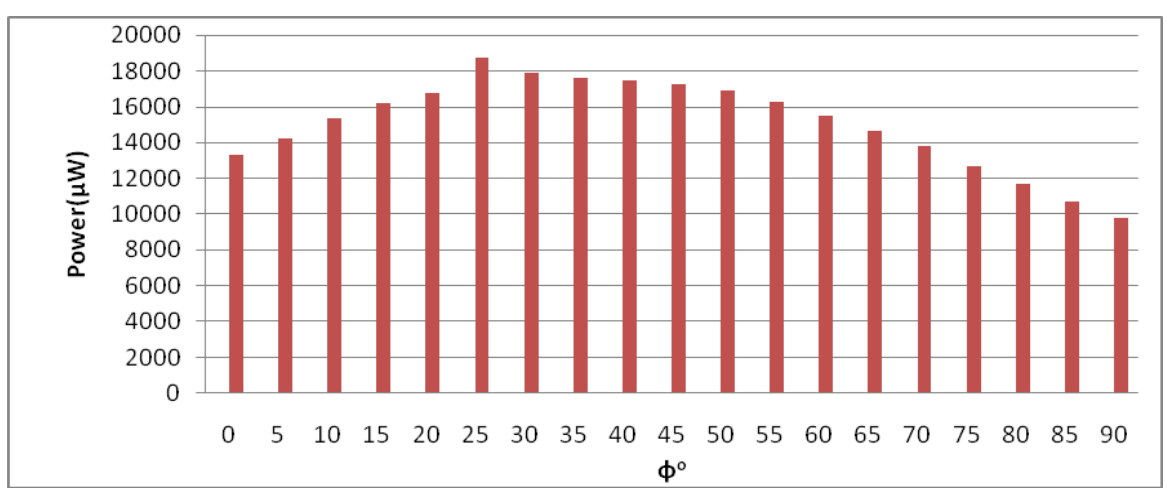

(c)

Figure 3. Shows the best three angles and maximum power in three different times for (a) $\theta=340^{\circ}$ south , $\mathrm{T}=17^{\circ} \mathrm{c}$, at time $=7: 30$, Rain.(b) $\theta=340^{\circ}$ south, $\mathrm{T}=20^{\circ} \mathrm{c}$, at time $=12: 00$, Rain. (c) $\theta=330^{\circ}$ south, $\mathrm{T}=17.3^{\circ} \mathrm{c}$, at time $=3: 00$, Cloudy. 
At first to six days we getting a data by using digital multi-meter, innovation and solar cell angles that is marked on the solar cell in three different times for exploring the best azimuth and altitude angle to use solar cell, we determined the best angles are for morning the azimuth angle $(\theta)$ is $340^{\circ}$ south and the solar cell altitude angle $(\Phi)$ is $27^{\circ}$, for noon the azimuth angle $(\theta)$ is $340^{\circ}$ south and the solar cell altitude angle $(\Phi)$ is $60^{\circ}$ and for evening the azimuth angle $(\theta)$ is $330^{\circ}$ south and the solar cell altitude angle $(\Phi)$ is $25^{\circ}$.

\section{4- Present work results}

By using those angles that is marked on the solar cell, the amount of power that is solar cell is gets is different in each angles, when angles is used from lower to higher, the solar cells output power increase from low to higher values, but in an angle solar cell gets maximum power, after that angle the solar cell power decrease step by step if we continue in changing solar cell angles to higher, due in that angle that is get us a maximum power, the light directly strikes on the solar panel .

The best angles that we are found are:

Incident angle $\varnothing=27^{\circ}$ time $=7: 30$ and Azimuth angle $\theta=340^{\circ}$ south.
Incident angle $\varnothing=60^{\circ}$ time $=12: 00$ and Azimuth angle $\theta=340^{\circ}$ south.

Incident angle $\varnothing=25^{\circ}$ time $=3: 00$ and Azimuth angle $\theta=330^{\circ}$ south.

The area of the solar cells has effected on the output power of it, because when increase the area of the cells gets higher amount of electrical power. The total area of the solar cell that is we use in our work is 25 square centimeter. When a different type of solar cell is used, then the absorption coefficient for light is different, that is means that the amount of output power will be different in each type it. In the limited range, when the temperature is increased then the output power of solar panel is increased.

On the other hand, the most important reason that has significant impact on the solar cell working is the weather, because the weather effects on the light intensity (energy) that converted to electricity. After finding the best Azimuth and incident angles for different times in Koya City. Their values are kept on these degrees for specified times. Then measurements were taken for three months. These graphs are shown below indicates the effect of the weather on the electrical output of the solar cell, where the fluctuations in the power over this period is due to the raining, cloudy and sunny days.

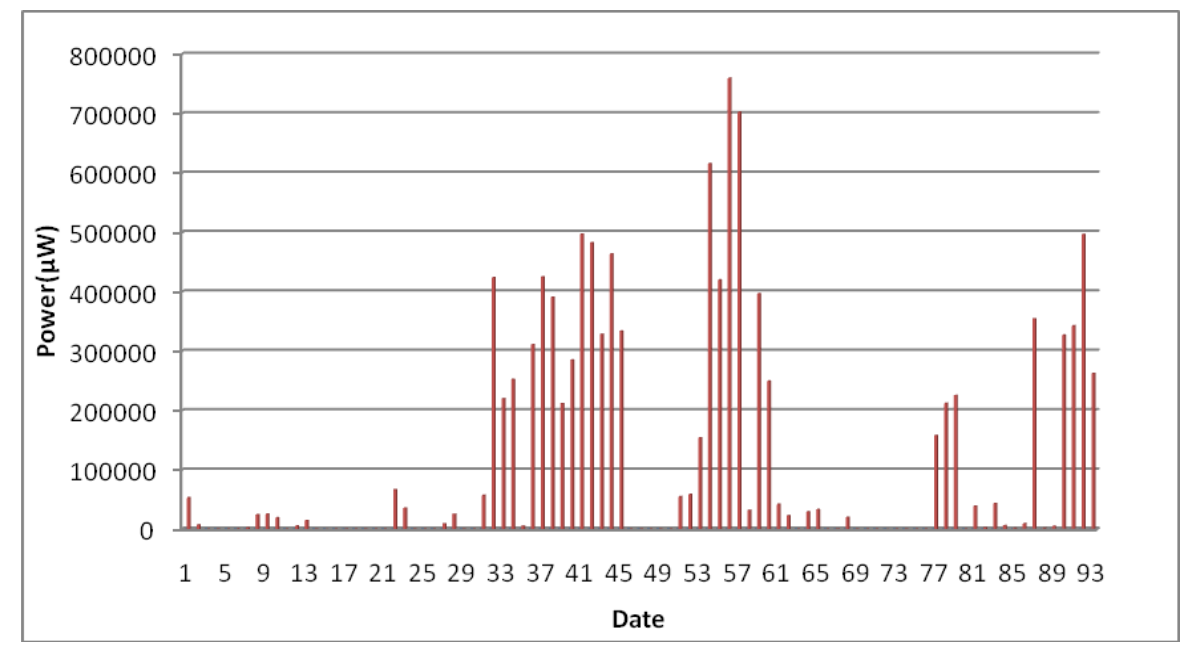

(a)

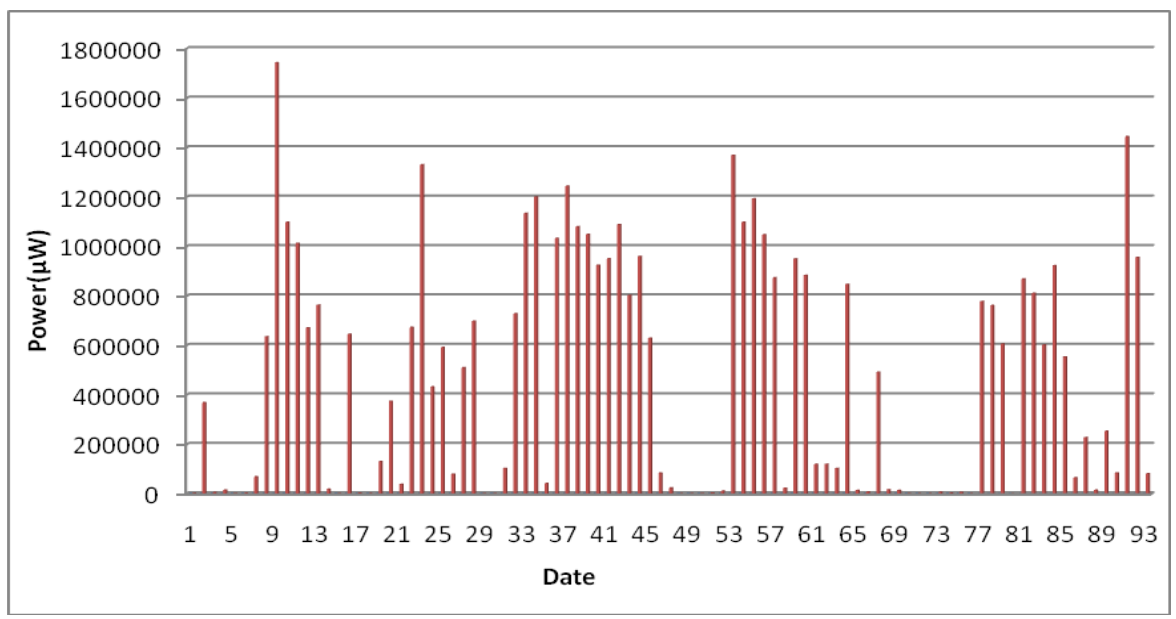

(b) 


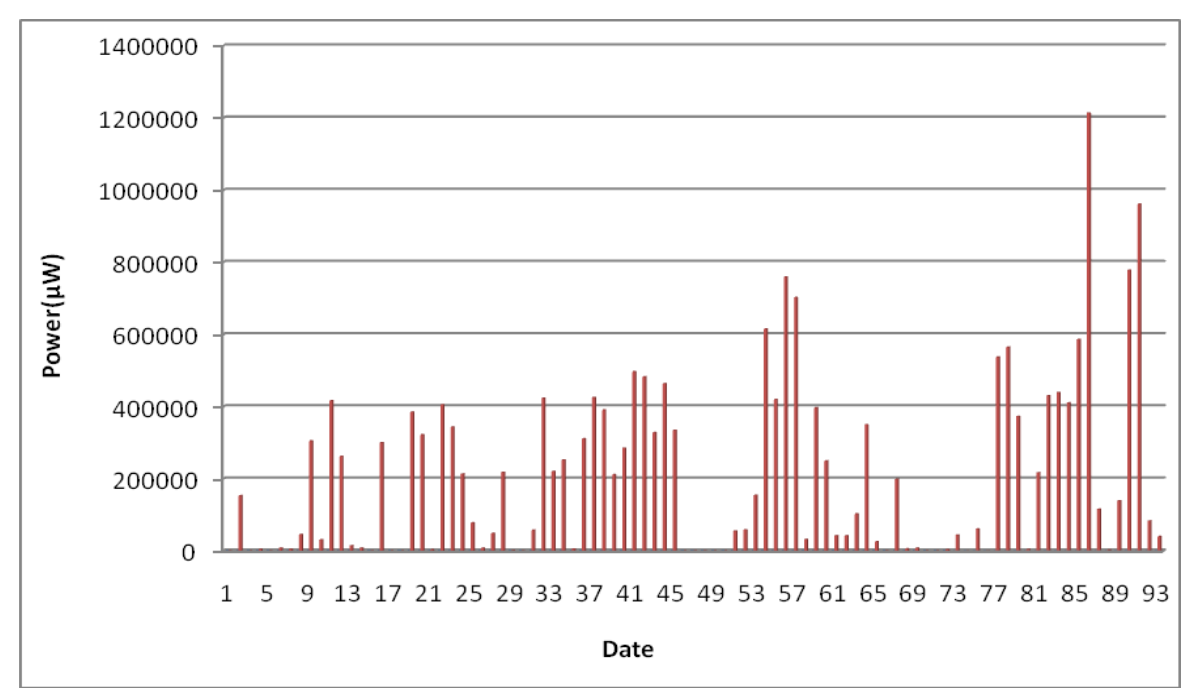

(c)

Figure 4. The effects of rainy, cloudy and sunny days on the output of the solar cells, measurements taken (a) at time $=7: 30$ am, (b) at time $=12: 00 \mathrm{pm},(\mathrm{c})$ at time $=3: 00 \mathrm{pm}$.

In the fig.(4) (a) On the $56^{\text {th }}$ day, at time $=7: 30 \mathrm{am}$, Temp $=7.8^{\circ} \mathrm{C}$, maximum electrical power was recorded because of weather was sunny, while on the $71^{\text {th }}$ day minimum power was recorded because of having a rainy and cloudy day and $\mathrm{Temp}=18^{\circ} \mathrm{C}$, (b) in the day 9 and at time $=12: 00 \mathrm{pm}$, we have maximum power because of the weather is sunny and $\mathrm{Temp}=26.4^{\circ} \mathrm{C}$ and in the day 50 we have minimum power because of in that day weather is rain and $\mathrm{T}=5.4^{\circ}$, (c) in the day 86 and at time $=3: 00 \mathrm{pm}$, we have maximum power because of in that day weather is sunny and Temp $=19^{\circ} \mathrm{C}$ and in the day 50 we have minimum power because of in that day weather is rain and Temp $=7.3^{\circ} \mathrm{C}$.

\section{Conclusions}

After examines the effects of those parameters which are mentioned in previous sections. It can be concluded that the best angles for installing a solar cell in Koya City are incident angle $27^{\circ}$ and azimuth angle $(\theta)$ toward the south is equal to $340^{\circ}$ at the morning, altitude angle $(\Phi)$ is equal to $60^{\circ}$ and azimuth angle $(\theta)$ toward the south is equal to $340^{\circ}$ at the noon, and altitude angle $(\Phi)$ is equal to $25^{\circ}$ and azimuth angle $(\theta)$ toward the south is equal to $343^{\circ}$ at the afternoons. The results shown in figures indicated that the electrical power depends on several reasons are: The type of the solar cell, The area of the solar cell, The azimuth and the altitude angles.

\section{REFERENCES}

[1] A. Goetzberger, C. Hebling and H.-Werner Schock/a review journal reports, Materials Science and Engineering R 40 (2003) 1-46 "Photovoltaic materials, history, status and outlook' Germany, Accepted 20 August 2002.

[2] www.irena.org, renewable energy technology: cost analysis series, volume 1: Power Sector, Issue 4/5 "Solar Photovoltaic's", IRENA(international Renewable Energy Agency), Abu Dhabi, United Arab Emirates, June 2012.

[3] Lewis, Nathan S., and George Crabtree. "Basic Research Needs for Solar Energy Utilization: report of the Basic Energy Sciences Workshop on Solar Energy Utilization, April 18-21, 2005."

[4] S. V. Szokolay, "Solar Geometry", University of Queensland, Department of Architecture, Brisbane 4072, ISBN 0867666344.

[5] http://solardat.uoregon.edu/cgi-bin/SunChart.cgi.

[6] http://www.reuk.co.uk/Measuring-the-Power-of-A-Solar-Pan el.htm. 